178

\section{UN SISTEMA PER LA GESTIONE INFORMATIZZATA DELLE EMOCOLTURE TEMPORIZZATE DA CATETERE VENOSO CENTRALE}

\author{
Venturi N.; Colombo L.; Galbiati E.; Brambilla P. \\ Servizio Universitario di Medicina di Laboratorio \\ Ospedale di Desio, via Mazzini I, 20033 Desio (MI).
}

Introduzione. Il sospetto d'infezione ematogena associata all'impianto di catetere venoso (CR-BSI: Catheter-Related Bloodstream Infections) frequentemente comporta la rimozione inappropriata del catetere. Il test per la valutazione del DTP (Differential Time of Positivity) per colture da sangue periferico da catetere rispetto a quello prelevato da vena periferica costituisce un metodo conservativo di riferimento per formulare una diagnosi d'infezione cateterecorrelata.

Blot e colleghi (Lancet 1999;354:1071-7) hanno definito che una differenza nel tempo di crescita superiore a 120 minuti è predittiva d'infezione da catetere venoso. Scopo di questo lavoro è stato quello di sviluppare un programma per la gestione informatizzata dei dati relativi alle emocolture temporizzate.

Metodi. Nel laboratorio dell'Ospedale di Desio il sistema automatico di rivelazione microbica per emocolture (BacT/ALERT3D; Biomerieux) in uso è collegato bidirezionalmente al server. Il risultato e l'orario di positivizzazione vengono registrati nel database centrale non appena inviati dallo strumento, insieme ad una serie di informazioni aggiuntive. Essi sono immediatamente disponibili per la consultazione telematica da parte dei medici dei reparti di degenza mediante l'accesso all'Intranet del laboratorio, e sono visualizzabili, per ogni singolo paziente, mediante un'apposita schermata.

Risultati. Dal Dicembre 2005, data di attivazione di questo servizio informatico, al Marzo 2007 sono stati segnalati 176 episodi di sospetta CR-BSI relativi a 89 pazienti. In 18 episodi su 176 sia la coltura da sangue periferico da catetere che quella prelevata da vena periferica risultavano positive per lo stesso microrganismo, di cui 15 (83.3\%; $8.5 \%$ del totale) con un DTP > 120 min. Le infezioni risultavano sostenute da batteri Gram positivi in 6 casi (40\%), da batteri Gram negativi in 7 casi (46.7\%) e da Candida spp in 2 casi (13.3\%). In 3 episodi (16.7\%) il DTP risultava inferiore a $120 \mathrm{~min}$.

Conclusioni. I risultati ottenuti concordano con le più recenti osservazioni sulle CR-BSI. L'archiviazione elettronica dei risultati relativi alle emocolture facilita la sorveglianza delle infezioni nocosomiali CVC-correlate.

\section{9}

\section{DUE PIATTAFORME ANALITICHE PER LA DETERMINAZIONE DELLA CARICA VIRALE DI HIV-I A CONFRONTO: bDNA versus Real-time PCR.}

\section{Amendola A., Brega C., Zaccaro P., Aleo L., Di Filippo S. Capobianchi M.R. \\ Laboratorio di Virologia, Istituto Nazionale per le Malattie Infettive "L. Spallanzani", Roma.}

Introduzione. Le performance analitiche del metodo COBASAmpliprep/COBASTaqMan (Roche Diagnostics), basato sull'amplificazione della regione gag mediante RT-PCR in real-time sono state confrontate con quelle del sistema Versant 3.0 (Siemens Diagnostics) che sfrutta l'amplificazione del segnale mediante ibridazione con sonde oligonucleotidiche

Metodi. Confronto eseguito su pannelli standard a titolo noto (BBI Diagnostics) e 90 campioni clinici di plasma [30 ospitano il sottotipo ricombinante di HIV-1 CRF02 (A/G); i restanti 60 campioni sono considerati virtualmente di sottotipo B]. Analisi statistica con metodo di correlazione di Pearson e con il plot Bland\&Altman.

Risultati. Nel complesso, il numero di campioni clinici con risultati discordanti riguardo alla positività/ negatività non supera il $6 \%$.

Riguardo agli aspetti quantitativi, il coefficiente di correlazione tra i risultati ottenuti risulta molto elevato, sia con i campioni clinici, sia con i pannelli standard ( $r>0.970$, $p<0.0001)$ e le differenze di misurazione sono statisticamente non significative. Nei campioni CRF02+, i valori ottenuti con real-time PCR sono più elevati di quelli ottenuti con bDNA, con una differenza significativa tra le medie pari a $0.245 \log _{10} \mathrm{cp} / \mathrm{ml}(p<0.05)$. L'analisi di Bland\&Altman evidenzia che tali differenze di misurazione si osservano principalmente nei campioni CRF02+ che contengono una quantità di carica virale compresa fra 3 e $5 \log _{10} \mathrm{cp} / \mathrm{ml}$. Invece, nel gruppo di pazienti di sottotipo B, le differenze maggiori si apprezzano intorno a valori elevati di carica virale $\left(>4 \log _{10} \mathrm{cp} / \mathrm{ml}\right)$.

Conclusioni. Nonostante l'elevata correlazione, i risultati ottenuti con i due metodi non sono sempre sovrapponibili: in genere, il metodo real-time PCR misura valori più bassi di HIV RNA per valori medio-alti di carica virale per il sottotipo B, mentre per il sottotipo CRF02 si osserva una sovrastima nell'intero range dinamico di misurazione.

E'necessaria una ulteriore sperimentazione per valutare l'impatto sui processi diagnostici, la performance su forme varianti di HIV-1 e la eventuale influenza sulle decisioni cliniche. 